\section{A 61}

AMPHETAMINE ABUSE DURING PREGNANCY. FOLLOW-UP OF CHILDREN AFTER 14 YEARs. Margareta Eriksson, Lars Cernerud, Björn Johnson, Gun Stenerot Rolf Zetterström. Department of Pediatrics, Karolinska Institute, St Göran's Hospital, Stockholm, Sweden.

Sixtyfive children born to women who all used amphetamine during preg nancy have been followed prospectively since birth 1976-77. The children have been tested and examined regularly, demonstrating that socia environmental factors influence the child's growth and somatic status while exposure for amphetamine during fetal life seem to influence the child's test results and behaviour up to the age of 8 years.

After 14 years information was collected about school achievement, health, somatic growth and psycosocial environment. Only 20 childre (30\%) were still in the custody of their biological mothers.Ten children (15\%) were one class below that for their biological age. Corre sponding figure in Sweden is $<5 \%$. Grades in language, mathematics and sports were significantly lower than the mean of their schoolmates. The difference was most pronounced in boys. Weight and length were decreased in girls and increased in boys in comparison with Swedish school children born in the same year. Socioenvironmental risk factors correlated with poor outcome.

Amphetamine abuse during pregnancy will influence the development of exposed children up to the age of 14 years.
64

THE INFLUENCE OF CHRONIC ATOPIC ECZEMA ON CHILD BEHAVIOUR AND MOTHERS ATTITUDE TOWARDS HER CHILD IN THE FIRST THREE YEARS OF LIFE.

J.M. Fegert, J. Schulz, R.L. Bergmann, U. Tacke, K.E. Bergmann, U. Wahn; Virchow-University-Clinic, Platanenallee 23, D-14050 Berlin. Data: In 1990 a birth cohort (N:1314) was assembled out of 7609 newborn infants from 5 German cities. To observe the natural course of a.e. the infants are medically examined 7 times from birth to their 3rd year of life. Additionally, data on infant's health, development, temperament and behaviour (CBCL 2-3), family climate, as lopment, temperament and behaviour (CBCL $2-3$ ), family climate, as onnaire. Results: Within the first 18 months $11 \%$ of the infants showed clear signs of a.e. at one point in time, $4,5 \%$ several times. showed clear signs of a.e. at one point in time, $4,5 \%$ several times.
In view of prevalence rates about $40 \%$, sleep problems appear to be In view of prevalence rates about $40 \%$, sleep problems appear to be
rather frequent between 6 and 24 months. When controlled for the infants's place of sleep and breast feeding. Parents of children with a.e. reported significantly $(p .<.05)$ more often sleep problems at 6 $(68 \%)$ and $18(72 \%)$ months but only if they slept together with their child. Children with chronic a.e. (at 6 and 12 months) were given the highest mean score on a difficulty scale (ANOVA: $F=4,7$ $\mathrm{df}=2, \mathrm{p},<.02$ ). Conclusion: Although sleep problems in infancy are common a.e seems to enhance their prevalence. As a result of severe forms of a e mothers perceive their infant's behaviour to be more difficult.

\section{$\Delta 62$}

IBUPROFEN AND PARACETAMOL

EFFECTIVE ANTIPYRETICS IN CHILDREN WTTH FEBRILE SEIZURES.

Arjen van Esch ${ }^{\dagger}$. Henriëtte A. van Steensel-Moll, Ewout W. Steyerberg',

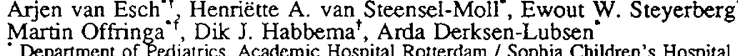

+ Department of Pediatrics, Academic Hospital Rotterdam / Sophia Children's Hospital

Introduction The possibility to reduce the risk of febrile seizure (FS) recurrences

with antipyretics has gained interest. To compare the antipyretic efficacy of

Ibuprofen and Paracetamol in children with FS we performed a randomized, multiple

dose, double blind, cross-over clinical trial. Study medication was either Ibuprofen

syrup (5mg/kg per dose) or Paracetamol syrup (10mg/kg per dose) at 6 hours

intervals during two days. No antibiotics were prescribed.

Participants/Measurements 70 patients with a history of FS (mean age 2.1 years) were assigned to treatment at the occurrence of a fever with rectal temperature $\geq$ $38.5^{\circ} \mathrm{C} .22$ patients were included during two fevers. Temperature was recorded at $0,2,4,6,12$ and 24 hours after the first dose. Temperature at 4 hours, overall mean temperature and the highest temperature during treatment were evaluated. Covariance analysis corrected for base-line temperature, age, weight and clinical fever diagnosis. Main Results Ibuprofen lowered temperature from $39.1^{\circ} \mathrm{C}$ base-line to $37.7^{\circ} \mathrm{C}$ overall mean, Paracetamol from $39.2^{\circ} \mathrm{C}$ to $38.0^{\circ} \mathrm{C}$. Ibuprofen showed $0.50^{\circ} \mathrm{C}$ more fever reduction at 4 hours after the initial dose $(\mathrm{p}=0.04)$. Also, overall mean temperature was $0.26^{\circ} \mathrm{C}$ lower and the highest temperature was $0.30^{\circ} \mathrm{C}$ lower during Ibuprofen treatment. In cross-over analysis respective differences were 0.66 ${ }^{\circ} \mathrm{C}(\mathrm{p}=0.03), 0.40^{\circ} \mathrm{C}$ and $0.36^{\circ} \mathrm{C}$ in favour of Ibuprofen. Two febrile seizures occurred during Ibuprofen treatment and three during Paracetamol treatment. Conclusions lbuprofen and Paracetamol are effective antipyretics in children with a history of FS. In the studied doses Ibuprofen reduces fever more than Paracetamol. Future clinical trials may determine the value of antipyretic treatment as a prophylaxis of recurrent febrile seizures.

\section{$\triangle 63$}

WONE MANERAL DENSTTY IN CHILDREN AFTER RENAL TRANSPLANTATION

Janusz Feber*, Pierre Cochat, Pierre Braillon, Catherine Glastre, Louis David Department of Pediatrics, Hospital Edouard Herriot, Lyon, France

*1st Pediatric Clinic, Hospital Motol, Prague, Czech Republic

Successful renal transplantation is supposed to correct the majority of bone minera metabolism disturbances induced by chronic renal failure. We examined bone minera density (BMD) in 14 children ( 8 girls, 6 boys) aged $8 \pm 4$ years at the time of rena transplantation (Tx). Dual energy X-ray densitometry of lumbar vertebrae (L1-L4) was performed within one year preceding Tx (T0), 6, 12 and 24 months after Tx (T6, T12 and $T 24$ respectively). The results of BMD obtained in $g$ of hydroxyapatite per $\mathrm{cm}$ of spine projected area were subsequently transformed to $Z$ scores $(Z)$ for norma pediatric population. All patients had a well functioning renal graft at $\mathrm{T} 6, \mathrm{~T} 12$ and T24, median serum creatinine levels were 54,63 and $84 \mu \mathrm{mol} / 1$, respectively. BMD \pm SD decreased from initial level of $0.65 \pm 0.18$ at T0 to $0.59+0.16$ at T6 (p < $0.05)$. BMD \pm SD measured at T12 $(0.61 \pm 0.15)$ and $T 24(0.67 \pm 0.16)$ was not significantly different from TO. Similar significant $(\mathrm{p}<0.01)$ decrease of BMD expressed in median $Z$ was observed between T0 $(0.19)$ and Tó $(-1.04)$, remained significantly $(p<0.01)$ lower at T12 $(-0.93)$ and increased to -0.52 at T24 $(p<0.0$ vs T0). In conclusion, children after kidney transplantation experienced a significan decrease of bone mineral density during the tirst 6 months after operation despite normal graft function. Progressive improvement of BMD was noted 12 and 24 months after $T x$

\section{5}

RECEPTORS FOR PHAGOCYTOSIS AND ADHESION ON NEUTROPHIL GRANULOCYTES IN NEWBORN INFANTS.

Gustav Fjaertoft, Uwe Ewald, Tony Foucard, Lena Håkansson, Per Venge.

Depts of Pediatrics and Clinical Chemistry, Uppsala University Hospital, Uppsala, Sweden.

Newborn infants have an increased susceptibility to serious infections. Neutrophil granulocytes play an important role in the defence against infections. We have studied the expression of the receptors for phagocytosis and adhesion (CD11b, CDI6, CD18, CD32, CD35 and Leu8) on neutrophil granulocytes from newborn infants and compared with results found in adults.

Subjects and methods: Blood samples were taken from 18 term newborn infants (cord. blood) and 30 healthy adults. The granulocytes were fixed with formaldehyde and incubated with monoclonal antibodies against each receptor. The cells were then analyzed by flow cytometry (Epics Profil II).

Results: For CD11b, CD16, CD18, CD32, and Leu8, there was no significant difference in receptor expression between granulocytes from newborns and those from adults. There was a trend towards increased expression of the $C D 35$ receptor $(p=0,068)$, and the expression of CD16 was significantly decreased $(p=0,046)$ on granulocytes from newborns.

Conclusion: With exception for a tendency of an increased expression of the complement receptor CD35 and a decreased expression of the Fc-receptor CD16, no significant differences were found between newbom infants and adults. 